\title{
Arquitetura eclética no Brasil: o cenário da modernização.
}

Annateresa Fabris.

ECA/Universidade de São Paulo

Duas avaliações do ecletismo, que datam dos anos 40 do nosso século, nos ajudarão a entrar no cerne de uma questão que só recentemente tem começado a ser revista, em nome não dos valores funcionalistas e sim da ideologia própria do século XIX. As duas avaliações que iremos examinar são essencialmente negativas, mas é justamente sua negatividade que nos interessa porque, a partir dessa categoria, poderemos começar um processo às avessas, que nos permita compreender as razões do ecletismo oitocentista.

A primeira leitura é brasileira, de autoria de Francisco Acquarone, que percebe a arquitetura do século XIX alicerçada no abandono do "colonial verdadeiro" em prol de "uma infinidade de casas horriveis", caracterizadas por platibandas ornadas com compoteiras e bolas. Ao lado delas, destacavam-se "fortalezas medievais", cheias de pedras e outros atentados, exibindo fachadas de ladrilhos ou pintadas de 'mármore fingindo'. Sobre os telhados começaram a aparecer em certa época, cúpulas arredondadas, casas que lembravam caricaturas da igreja de São Pedro em Roma...". Nem mesmo a oportunidade representada pela abertura da Avenida Central conseguiu melhorar a situação: o mestre-de-obras continuava a ser o "senhor absoluto" da arte de edificar, repelindo os arquitetos do campo de ação e impondo seus critérios de gosto (Acquarone 1980:142-143).

Se a análise de Acquarone se pauta por uma visão de superfície, atenta tão somente a valores formais, a de Pevsner, ao contrário, é essencialmente sociológica. As razões do ecletismo devem ser buscadas na reação à Revolução Industrial, na ascenção de uma nova classe em busca de status, no crescente individualismo, na nostalgia do "longínquo" posta em voga pelo 
1. N. Pevsner (1970:200-202). Para justificar a arquitetura pós-moderna, muitas vezes tachada de eclética, Jencks estabelece uma distinção entre o século XIX e a atitude atual. O ecletismo do século XIX foi freqüentemente ditado pelo oportunismo mais do que pela convicção; suas motivações são o capricho e o conforto, objetivos insuficientes para se pensar a arquitetura como um todo. Trata-se de um ecletismo "fraco", escassamente dotado de teorias, ao qual se opõe o ecletismo hodierno, dotado da possibilidade de desenvolver uma variedade mais forte e mais radical. Este ecletismo é considerado "radical" por Jencks (1984:127-128)
Romantismo. Na visão de Pevsner, o elemento determinante do ecletismo é o encomendante, em geral novo rico, despido de qualquer laivo daquela cultura aristocrática que caracterizara o século anterior. É tendo em mente esse quadro de referências que escreve o historiador inglês:

\begin{abstract}
"A incultura e o individualismo são as características do novo rico vitoriano. Se, por uma razão qualquer, um diretor de fábrica tiver-se apegado a um estilo, nada o impedirá de mandar construir sua casa, seu ateliê, seu escritório, seu clube, naquele estilo. Infelizmente, as pesquisas efetuadas pelas geraçōes anteriores tinham sido tão numerosas e tão variadas, os amadores do século XVIII tinham explorado tantas formas fantasiosas, proposto tantos estilos, os poetas românticos se compraziam com tantos sonhos nostálgicos do longínquo no tempo e no espaço que os novos mecenas só tinham a dúvida da escolha. (...) Assim chegamos, por volta de 1830, a um impasse estético e sociológico na arquitetura. No espírito dos arquitetos, toda criação anterior à idade industrial é preferivel, por princípio, à menor tentativa de exprimir o caráter da própria época. Os clientes deixam-se levar por imperativos que não têm nada a ver com a estética, que não sentem, deixam-se seduzir pela associação das idéias. Mas, num ponto, são iguais para julgar e dar sua opinião: a ortodoxia da imitação. A livre interpretação dos estilos dá lugar à exatidão arqueológica. É uma coincidência se assistimos ao mesmo tempo ao nascimento das ciências históricas que caracterizam o século XIXé É, na verdade, o século da historicidade. Após o século XVIII, que construía sistemas, o século XIX contenta-se com um estudo histórico e comparativo das filosofias existentes em lugar do estudo da ética ou da estética em si. O mesmo acontece com a teologia e a filosofia. Graças à divisão do trabalho, que a arquitetura, como todas as outras artes, letras e ciências, aceitou da indústria, o arquiteto podia desenhar a partir de um repertório imenso de detalhes históricos. Não há nada de surpreendente no fato de que o século XIX não tenha perseguido a busca de um estilo original" 1 .
\end{abstract}

Uma vez que o argumentos de Pevsner são bem mais ponderáveis que os de Acquarone, partiremos deles para começar nossa reflexão sobre o ecletismo, pois eles enfeixam algumas questões fundamentais para a compreensão do fenômeno que nos interessa de perto.

Pevsner tem razão quando detecta no século XVIII uma matriz da atitude eclética. É, de fato, a postura investigativa do lluminismo, sua concepção da cultura como conquista, troca e mensagem, sua necessidade de rever os estilos do passado, inclusive o clássico, à luz do presente que permitirão a disponibilidade e a multiplicidade que caracterizarão o século seguinte. Alguns exemplos serão suficientes para comprovar esșa afirmação. Piranesi, consciente da relatividade da fruição artística, propõe outros modelos referenciais que não o romano, mostrando interesse pelos estilos grego, egípcio e etrusco que, combinados entre si, proporcionariam o aparecimento de novos ornamentos e de novas maneiras arquitetônicas. Uma outra vertente - a poética do pitoresco mostra igualmente uma atenção de caráter eclético para com o passado. Se Milizia propõe combinar nas ruínas "edificações antigas e modernas, rústicas e senhoris", Algarotti, por sua vez, aponta modelos possiveis para os cenógrafos nos exemplos romanos, gregos, egípcios e na arte da China, da qual poderiam brotar "inteligentes misturas de hórrido e agradável". Griseri e Gabetti 1973:5-6, 14-15, 36-37).

gosto cenográfico não se restringe ao teatro. Numa época caracterizada por uma troca constante entre artes plásticas e literatura, Horace 
Walpole pode ser considerado um verdadeiro iniciador da atitude eclética: a partir de 1753, dá vida, em Strawberry Hill, a uma faustosa cenografia, enraízada no gosto pelo estranho e pelo fantástico. Ao transformar sua casa de campo num castelo, Walpole produz um homólogo do primeiro romance gótico, coincidentemente de sua autoria, O Castelo de Otranto (1764). Vendo no gótico a moldura ideal da exaltação sentimental e dramática, Walpole pauta sua reforma pela adesão ao estilo medieval, atraído não por razões estruturais, mas por seu "ar de novidade caprichosa", sem esquecer elementos rococós e chineses, sobretudo nas partes decorativas (Griseri e Gabetti 1973:52-53; Pevsner 1970:177).

A relação com o passado de Piranesi, Milizia, Algarotti, a atitude evocativa de Walpole ganham intensidade no século XIX que, sob o signo da história, gera os meios que the permitem dominar aquela grande quantidade de fatos, imagens e idéias com a qual a sociedade era constantemente confrontada. Não se pode esquecer que novos meios de difusão acrescem enormemente o cabedal de conhecimentos do homem oitocentista. Jornais, revistas, manuais, enciclopédias, livros ilustrados, a divulgação de imagens e repertórios através de gravuras e fotografias, o crescente interesse pelo romance histórico, o papel do melodrama na constituição de um imaginário pitoresco colocam o homem do século XIX no interior de uma rede de relações', que the permite transitar livremente entre passado e presente, sem se preocupar com a adesão a este ou àquele momento da história por estar potencialmente aberto a todos eles.

Pensando a questão por esse ponto de vista, parece ser difícil concordar com Pevsner quando este se refere à "ortodoxia da imitação". A questão da imitação no século XIX inscreve-se muito mais na vertente da citação sem aspas, da alusão do que naquela da retomada fiel do passado. Paradoxalmente, a modernidade da atitude eclética é atestada por sua relação com o passado, como comprovam Argan e Mignot.

O historiador italiano descarta as etiquetas de conservadores e reacionários para os sucessivos revivals do século XIX: estes não são conservadores porque não se pautam pelos princípios tradicionais, assim como não são reacionários, posto que renegam a idéia de autoridade. A vólta ao passado não é filológica e sim regrada pelos ritmos da moda, pelos padrões de consumo da produção industrial, cujos materiais são integrados a um léxico arquitetônico fantasioso (Argan 1974:8).

Mignot (1983:309), por sua vez, fala de um movimento "duplamente retrospectivo e prospectivo", que vê os arquitetos experimentarem os novos materiais e os novos programas da sociedade industrial e descobrirem ao mesmo tempo os valores arquitetônicos do passado, adaptados às exigências contemporâneas.

O testemunho de um observador atento como jules Verne explicita claramente o "duplo movimento" a que faz referência Mignot. No relato da viagem à Inglaterra e Escócia, empreendida em agosto de 1859, escreve o autor francês: 
"A julgar pelo seu interior, o castelo devia exibir a arquitetura gótica que os saxões tanto popularizaram. Afora isso, era inteiramente moderno e em pleno vigor de sua juventude. Essa forma particularmente caprichosa permite total liberdade às fantasias do arquiteto, e, se ele for inglês, sacrificará tudo pelo conforto. De fato, ele porá uma porta onde ela ficar mais cômoda, a janela onde oferecer as mais belas vistas. Disporá as salas e os quartos da maneira mais vantajosa; o teto de uma sala será suspenso, o de um escritório rebaixado; um canto gracioso será instalado junto de uma ampla galeria. Desse conjunto resultará uma fachada irregular que, em suas próprias irregularidades, será encantadora, desdenhando as linhas arquitetônicas em favor de um imprevisto a que não falta um certo estilo. Esses pequenos castelos góticos são numerosos na Escócia, e admiravelmente apropriados ao uso que deles é feito e ao clima do pais" (Verne 1990:129-130).

O que a atitude poliestilistica do ecletismo denota não é apenas um fato artístico, mas uma nova organização social e cultural, que põe fim a toda e qualquer idéia de unidade para apontar para o múltiplo, o diversificado, para privilegiar o instável e o relativo em detrimento do absoluto e do eterno. Sua metodologia fundamental consiste na decupagem, na concepção da arquitetura como linguagem dotada de valores simbólicos e emotivos que deveriam ser transmitidos a todas as camadas da sociedade. Muito significativo nesse sentido é um texto de 1904, de autoria de John Belcher, que associa a arquitetura à escrita:

"A arquitetura é a prosa do pensamento e sentimento inarticulados, mas belos. Às vezes, fala do trivial na vida; subindo mais alto, fala de paz doméstica e felicidade; e, numa dicção ainda mais sublime, realça os mais nobres e os mais amplos objetivos da vida. Relata o passado, registra o presente e propõe ideais para o futuro. Mas só quando é enriquecida pelas artes irmãs - escultura e pintura - pode contar a história com a plenitude da eloqüência e do poder" (Griseri e Galbetti 1973:97-98; Olsen 1986:281-283).

A reflexão de Belcher coloca-nos de imediato no centro de uma das questões fundamentais do ecletismo - a da representação, a da teatralização da vida. Não é por acaso que sua manifestação mais importante se concentra na fachada. A idéia dominante do século XIX é de que a arquitetura deve ser representativa, de que deve evidenciar através da forma exterior e da estrutura o status de seu ocupante, seja ele o Estado, seja ele o indivíduo particular. É por isso que a decoração se torna um elemento indispensável a ser usado em larga escala, que se multiplica a função ilusionista dos materiais, que o erudito e o pitoresco se mesclam: é necessário sublinhar o caráter de obra de arte total inerente à cidade e nada é mais adequado do que pontilhá-la de monumentos. Por vezes, a fachada funciona como uma grande litografia, impregnada pela dimensão do desenho, como percebe Hayward ao visitar Paris no começo do Segundo Império (Olsen 1986:263).

Se se assiste ao domínio da arquitetura como força de coesão da sociedade, nem sempre, porém, as obras ecléticas são fruto exclusivo do trabatho do arquiteto. Ao lado do profissional especializado destaca-se a presença de um grupo crescente de autodidatas, que transpõem o debate e a prática da arquitetura para fora do círculo restrito da academia. É também essa ampliação 
do quadro profissional que explica a multiplicidade de modelos e referências utilizados pelo ecletismo. "Com a ampliação dos meios de divulgação, que transforma todo artista eclético numa espécie de "pesquisador científico" (Griseri e Gabetti 1973:731, com a facilitação e o barateamento das viagens, o imaginário do construtor do século XIX alcança uma dimensão, desconhecida até aquele momento, multiplicando ao infinito os tipos e os modelos à disposição do arquiteto e de sua clientela.

Confrontado com os mais variados modelos, o arquiteto oitocentista deixa de lado toda idéia de absoluto para operar a partir de um ponto de vista relativo, que leva em conta a relação da arquitetura com as exigências do momento histórico. A arquitetura eclética não é apenas representativa: está também atenta ao caráter funcional dos ambientes e dos objetos, entendidos antes de tudo "como um valor que possa coincidir com um conforto estetizante", como demonstram Griseri e Gabetti. Contemporaneamente a arquitetura eclética voltase para o passado: como afirmava César Daly, sua vida estava enraízada na tradição. Uma tradição atenta ao presente, que Daly percebe como eclético em todas as manifestações da vida social. Se o ecletismo não é capaz de criar uma arquitetura semelhante à grega ou àquela da Alta Idade Média, é, porém, a expressão mais adequada ao século XIX, passivel de evolução de acordo com o futuro desenvolvimento da história (Griseri e Gabetti 1973: 102; Olsen 1986:301-302).

Pode-se perceber por essa breve introdução que a questão eclética não é um fato que interessa apenas à história da arquitetura. Diríamos antes que o ecletismo é um fenômeno mais vasto, que requer uma abordagem interdisciplinar, na qual se entrecruzem a história das mentalidades e a história da arquitetura com vistas não ao estudo do monumento isolado, mas a uma concepção particular do espaço urbano, que deita raízes em ideais como magnificência, expressividade, monumentalidade com a intenção de glorificar uma ideologia ou uma classe.

Transpor essas reflexões para o Brasil revela-se bastante problemático porque a situação atual dos estudos sobre o ecletismo não permite ainda uma abordagem capaz de responder a muitas das questões apontadas anteriormente.

$\mathrm{Se}$, tal como na Europa, o edetismo é o estilo próprio de uma modernidade que lida sem problemas com o passado, não se pode esquecer que, no nosso caiso específico, o passado para o qual os arquitetos se voltam não é nacional. A afirmação do ecletismo no Brasil não implica em conhecimento da tradição anterior e sim o rechaço radical dos vestígios coloniais que persistiam no país, apesar do neoclassicismo da Missão Artística Francesa. Esse fato não pode ser imputado apenas à presença maciça de imigrantes no país nas últimas décadas do século XIX, que, portadores de outras concepções e de outros costumes, acabam por impôtos ao novo habitat.

Guiar-se apenas por essa idéia significaria falsear o problema ou, pelo menos, apresentáto de maneira muito parcial. O papel do imigrante é, com efeito, fundamental, tanto que Heliana Angotti Salgueiro considera tal fato decisivo na definição perfil da arquitetura brasileira em fins do século XIX (Salgueiro 1986:36). 
Mas, a par dele, não se pode esquecer que igualmente importante é o critério de gosto da elite dirigente, que deseja reproduzir no Brasil tipos e modelos admirados na Europa.

Quando se aponta para esse fato não se deseja, porém, liqüidá-lo rapidamente como faz Yves Bruand, que considera a arquitetura brasileira do início do século XX destituída de originalidade, interessada tão somente na imitação "de obras de maior ou menor prestígio pertencentes a um passado recente ou longínquo" ou em "meras cópias da moda então em voga na Europa", a exprimirem "um complexo de inferioridade" (Bruand 1981:33).

Falar em "complexo de inferioridade" implica reconhecer validade à velha teoria da dependência, quando outra tarefa se impõe nos dias de hoje: a de detectar as razões do "desejo de ser estrangeiro", daquela sede de cosmopolitismo que toma conta do Brasil sobretudo após o advento da República. Os lemas do Brasil republicano são progresso, indústria, capital, modernização. Neles inscreve-se uma noção de prosperidade que oblitera contrastes e conflitos, ao projetar nas criaçōes culturais a vontade de mascarar ou cosmetizar as tensões que caracterizavam o período.

Se esses são os pressupostos da noção de modernidade que se impõe no Brasil na virada do século, não cabe pensar num simples movimento mimético de caráter compensatório, nem na adoção pura e simples de um modelo cultural "inautêntico" porque a problemática é bem mais complexa, como demonstra Maria Isaura Pereira de Queiroz. Quando se discute a questão da "importação cultural", não basta notar o fenômeno. E necessário verificar de que modo ocorreu a importação: que elementos foram escolhidos, como foram adotados, qual foi o produto final de tal operação. Como afirma a autora:

\footnotetext{
"toda adoção era orientada pela vivência daqueles que a efetuavam, pelos problemas com que se defrontavam, pela sua experiência de vida cotidiana, e se dava, pois, norteada pelo contexto nacional. (...) Tais elementos provindos do exterior provavelmente estariam correspondendo a algo que seria parte integrante de nossa sociedade, razão pela qual tinham sido buscados; só assim se descobriria também a que 'falta' estariam em correlação, e porque não teria havido, para sanáta, uma invenção do próprio grupo" (Queiroz 1981:252).
}

À luz de tais idéias, é, possivel compreender melhor a operação fundamental da "ideologia Belle Époque", atenta sobretudo à criação de um cenário faustoso, no qual o artefato cultural é um símbolo funcional e ornamental ao mesmo tempo, desempenhando um "papel cosmético", a cujos anseios responde plenamente a arquitetura de importação.

País mestiço que se sonha branco, país que começa a experimentar o processo industrial e já se crê plenamente moderno, o Brasil de fins do século XIX deseja romper de vez com o estatuto colonial, projetando-se integralmente num modelo econômico e cultural que the permitiria superar de imediato um passado com o qual não se identificava e que procura apagar, sem rodeios, como comprova a remodelação do Rio de Janeiro quando da construção da Avenida Central.

A Avenida, símbolo da modernidade alcançada às custas da destruição da "tradição do mau gosto e da imundície"- como afirma Bilac em 1905 - 
configura claramente a forma mentis eclética ao voltar-se para a espetacularização do espaço urbano e ao concentrar toda a atenção nos elementos constitutivos do cenário. É sintomática a realização de um "concurso de fachadas", no qual a liberdade estilística vem acompanhada pela imposição de normas de edificação aptas a coibirem a construção de "casas acanhadas".

A prescrição é mais profunda do que se poderia acreditar à primeira vista. Proibir as "casas acanhadas" não significa apenas fazer passar para um segundo plano o eclético vernáculo com suas compoteiras e com o estilo chalé. A condenação dos "medonhos vasos de cimento" e das "janelas de peitoril" é paralela ao repúdio de seu agente - o mestre-de-obras-, ao qual o empreendimento da Avenida Central contrapõe o trabalho das companhias construtoras (vide Del Brenna 1987:54-56), num claro processo de formalização dos princípios da economia capitalista, que desmente as afirmações de Acquarone referidas anteriormente.

A vontade de ser moderno a todo custo faz aceitar com entusiasmo os produtos de uma indústria, que, na Europa, eram as mais das vezes disfarçados para não empanarem com seu "mau gosto" o brilho da arquitetura representativa. É o caso dos produtos da arquitetura do ferro, que recebem aqui acolhida positiva, para a qual podem ser aventadas duas hipóteses: trata-se de um material industrial que permite participar do mito do progresso; proporciona a construção de estruturas modernas, necessariamente belas. Isso se torna claro na descrição dos pavilhões do Mercado da Carne de Belém, feita por $A$ Província do Pará, que opõe a elegância das estruturas de ferro aos "monstruosos barracões de madeira" anteriores, que exalta ao mesmo tempo sua "feição artística" e a "utilidade do fim" a que se destinam (vide Costa 1988: 153-155).

Se, no caso da arquitetura do ferro, as recentes pesquisas de Geraldo Gomes da Silva e Cacilda Teixeira da Costa permitem remontar à gênese de muitas construções em termos de modelos referenciais, o mesmo não ocorre com a arquitetura em alvenaria sobre a qual não existem ainda pesquisas documentadas, que deem conta da formação e do universo de conhecimentos do arquiteto eclético. Sabemos, em termos genéricos, que são conhecidos no Brasil tratados como o Vignola dos proprietários, que circulam entre arquitetos e mestres-de-obras, publicações como L'Artista Moderno, La Costruzione Moderna in Italia, Facciate di edifici in stile moderno, mas não existe nenhum estudo preciso sobre a biblioteca de um arquiteto que nos permita compreender de fato o múltiplo universo de suas escolhas.

Esta, entretanto, é uma tarefa importante, uma vez que sabemos que muitos arquitetos ecléticos são autodidatas e o conhecimento de seu universo de referências seria determinante para compreender melhor os critérios de gosto que estão na base de sua formação. Só para dar um exemplo comparativo, que denota a importância do conhecimento das fontes de informação que compõem o imaginário do arquiteto eclético, lembraremos o trabalho de Griseri e Gabetti sobre Giovanni Schellino. Ao analisar sua biblioteca de arquiteto autodidata, os autores encontraram lado a lado os instrumentos de estudo e de atualização mais diversificados: tratados eruditos, textos didascálicos, divulgativos e 
populares, cartões postais, frontispícios de libretos, litografias de livros de viagem, gravuras de cenários teatrais, álbuns das exposições universais. Entre os livros mais consultados pelo arquiteto, destacam-se Sumário da história universal da arquitetura de E. von Sacken (1879), os tratados clássicos de Vignola, Milizia e Quatremère de Quincy, História da arte através dos monumentos de Séroux d'Agincourt (1811-20). Manual dos engenheiros, arquitetos, medidores com fórmulas, ilustrações e indicações práticas de J. Claudel (1852), todos com anotações autógrafas (Griseri e Gabetti, 1973:73-75), que permitem reconstituir seu background cultural e formativo.

Um sinal de que essa situação está para mudar entre nós é dado por Heliana Angotti Salgueiro em seu estudo sobre Belo Horizonte. Ao analisar a figura de José de Magalhães, arquiteto-chefe da construção da cidade, a autora destaca sua formação na Escola Nacional de Belas-Artes de Paris, após um primeiro "estágio" na Escola Nacional de Desenho e de Matemática. Mas a formação do arquiteto oitocentista não se limitava à Escola. Se esta tinha a seu cargo os estudos teóricos, a base da educação arquitetônica - desenho e projeto - era adquirida no ateliê de um mestre, Daumet, no caso de Magalhães. A partir da formação do arquiteto, baseada no conhecimento dos tratados de Palladio, Vignola e Scamozzi, Heliana Angotti Salgueiro traça um paralelo entre os projetos de Magalhães e os princípios norteadores da Escola de Belas-Artes. Um exemplo disso estaria nos projetos para os Palácios da Justiça e do Congresso, desenhados de acordo com a tradição acadêmica: a composição é simétrica no sentido de uma identidade bilateral, que investe tanto as alas direita e esquerda quanto as fachadas anteriores e posteriores dos edifícios (Salgueiro 1986:75-79).

Os exemplos da Avenida Central, de Belo Horizonte ou da própria arquitetura do ferro remetem-nos apenas às concepçōes oficiais. Mas, como já dissemos, o edetismo é também percorrido por um veio vernáculo, que lança mão de um repertório aprendido em catálogos, em revistas, em manuais, em cartões postais, baseado na lembrança ou nas técnicas artesanais ensinadas nas Escolas de Artes e Ofícios.

Os novos meios de divulgação, o surgimento de uma sociedade de massa, a expansão das idéias liberais impõem à arquitetura outras tarefas que não as tradicionais, denotando que uma mesma concepção de status informava todas as classes sociais e não apenas as mais abastadas.

Esse fenômeno deve ser compreendido à luz da função que a sociedade oitocentista confere à arte. Cabe a esta elevar o gosto e a moral, educar e edificar os habitantes de uma cidade com o espetáculo oferecido pela beleza. É por isso que César Daly insiste na "difusão liberal" da arte nos locais públicos e os arquitetos vitorianos apostam no poder de sugestão do ornamento (Olsen 1986:295).

Trata-se de uma questão claramente explicitada pelo contexto brasileiro. A função de representação conferida à arquitetura não diz respeito apenas às tipologias burguesas. Mesmo as camadas menos abastadas, que não podem se pautar pela monumentalidade, optam, entretanto, pelo ornamento, qualificando as fachadas de suas habitações com detalhes decorativos. 
A fusão de linguagens, tão típica do ecletismo, o interesse acentuado por novos ícones, a idéia de que a arte deve ser mais rica do que a realidade, a importância alribuída ao virtuosismo e à noção de abundância, os novos ritmos de fruição e consumo derivados da tecnologia industrial (Griseri e Gabetti 1973:100-102) repercutem também entre nós. Assiste-se nos bairros da classe média e mesmo em bairros mais populares ao surgimento de edificações estruturalmente simples, mas marcadas por detalhes decorativos, que sintetizavam as aspirações de prestígio e ascensão social de seus habitantes e a vontade de contribuir, na medida do possível, à qualificação e ao embelezamento da cidade, patrimônio comum imaginário de toda a sociedade.

O gosto pelo pitoresco, evidenciado na moda dos chalés e dos quiosques, que se impõe no último quartel do século XIX, faz parte desse quadro de referências. Tal como acontecera em Strawberry Hill, o pitoresco se caracteriza como elemento de "novidade caprichosa", acentuando, no nosso caso, a sensação de viver fora do Brasil. Lambrequins, estuques, ornamentos de ferro fundido são apostos a edificações tradicionais, denotando, ao lado do gosto pelo exótico, a vontade de ser moderno, proporcionada pelo uso de protótipos industriais. A fetichização de tais protótipos chega a tal ponto que se assiste à inversão de um fenômeno que caracterizara o uso do ferro na Europa. Se na Europa, o ferro era disfarçado de material nobre, gerando os veementes protestos de um Ruskin, no Brasil, há casos de colunas de madeira que fingem ser de ferro, atestando o desejo de participar de uma modernidade evidentemente simbólica.

Se a arquitetura vernácula participa da tarefa cosmética tanto quanto as expressões eruditas, não cabe a ela, entretanto, dar conta da ideologia fundamental do século XIX que se manifesta através do monumento. $O$ monumento diz respeito antes de tudo à esfera pública, como demonstra César Daly em 1862:

"O monumento público, o monumento que se dirige a todos, que pertence à nação ...deve satisfazer o sentimento geral, nacional de beleza... A beleza de um monumento público deveria ser uma emanação deslumbrante e direta do gênio vivo da sociedade, uma profissão de fé estética da raça" (apud Olsen 1986:291).

É em função dessa idéia que as cidades brasileiras são pontilhadas de monumentos belos e dignos, vazados nos grandes exemplos da arquitetura representativa. É por isso que a Escola Nacional de Belas-Artes se inspira no Louvre e os, Teatros Municipais do Rio de Janeiro e de São Paulo têm como claro modelo a Ópera de Garnier com seu léxico neobarroco.

A idéia do "monumento estético", que qualificasse artisticamente a capital do país, transparece do memorial de Francisco de Oliveira Passos, anexo ao projeto vencedor do concurso para o teatro carioca (1904). Descartando a "arquitetura ultramoderna" por ser "incompatível com a seriedade do edifício", Oliveira Passos explica sua escolha da Renascença francesa em termos de decoro - "é o estilo típico, para os edifícios destinados a teatro" -, não deixando de sublinhar que modernizara seu léxico por motivos econômicos e relaxara seu rigor, ao buscar no mourisco "uma variação para as cúpulas" lapud Del Brenna 1987:57-58|. 
Ao lado dos monumentos tradicionais, a arquitetura oitocentista exibe um novo tipo de monumento, fruto do progresso e da indústria - a estação ferroviária-. Ferro e alvenaria misturam-se em sua composição, o primeiro representando o aspecto técnico-funcional, a segunda providenciando - decoro e o ornamento, como testemunha o exemplo da Estação da Luz de São Paulo, totalmente planejada em Londres e cujos componentes vieram todos da Grä-Bretanha. Alfredo Moreira Pinto, num texto de 1900 - ano de conclusão das obras -, refere-se a uma "arquitetura dórico-italiana", a colunas e cimalhas em estilo coríntio, à plasticidade dos onnamentos de ferro, que considera "muito artísticos" (Pinto 1979:201-205).

Cacilda Teixeira da Costa (1988:1 16-1 17) explica o uso concomitante do tijolo à vista e do ferro por razões plásticas:

"A matéria, a cor, e o 'calor' dos tijolos envolvem e destacam a superfície lisa ou rendilhada dos ferros, resultando num grafismo que vibra delicadamente com a luz e dá suporte ao desenho e às sombras da ferragem. $O$ tratamento dos detalhes destaca este grafismo dos rendilhados de ferro ou revela as linhas da construção. Trata-se de um comentário plástico sofisticado que leva os olhos a definir os diferentes planos das estruturas ou a cadência rítmica criada pela repetição dos elementos decorativos em série. Neste edifício integra-se o interesse arquitetural e técnico. A utilização do ferro abrange também luminárias, instalações sanitárias, mobiliário, relógios e inúmeras peças e utensílios, cuịa inter-relação também está ligada ao efeito plástico do todo".

É em função da destinação do edifício, como viemos comprovando, que se definem as tipologias estilísticas mais recorrentes, entre as quais se destacam os modelos neoclássicos em sentido lato labarcando também o léxico renascentista) para as construções representativas; os modelos pitorescos para os chalés e os quiosques com as variações neogóticas e neo-românicas para as igrejas; os modelos menos eruditos e menos rigorosos, bem mais. fantasiosos do que os anteriores, verdadeiras colagens poliestilisticas que, por vezes, integravam fragmentos provenientes de demoliçōes de construções anteriores ou estilemas do Art Nouveau.

Esse mapa indicativo de algumas questões relativas ao ecletismo brasileiro seria incompleto se nele não inclúissemos o capítulo do neocolonial, fruto, em parle, da reação contra o estilo dominante a partir dos anos 10.

Marco inicial dessa campanha, que toma a si a tarefa de extirpar 0 "mau gosto" que assolava a arquitetura nacional, é a conferência de Ricardo Severo, "A arte tradicional brasileira", proferida a 20 de jutho de 1914. A data da conferência não poderia ser mais significativa: a Primeira Guerra Mundial vem precedida de um despertar nacionalista, que acaba por atingir o Brasil, levandoo a repensar suas questões artísticas, inclusive pela falta de matérias-primas e manufatos, em grande parte provenientes da Europa.

O caráter por demais internacional de cidades como o Rio de Janeiro e São Paulo começa a ser posto em questão. Vicente de Paulo Vicente de Azevedo caracteriza São Paulo, em 1920, como um "sujeito enriquecido", que "quis esquecer o seu passado materialmente modesto, mas honradamente honesto" (Azevedo 1920: 179). 
Ribeiro Couto, por sua vez, critica a adoção dos "confusos estilos 'par-

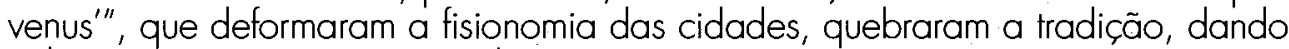
vida a "uma arquitetura mista, de mau gosto e inexpressiva" (Couto 1922).

Contra o mau gosto, contra os "aleiijōes" com pretensão a estilo, ergue-se um modelo de arquitetura robusta, forte, de linhas calmas e tranqüilas, na qual tudo "é estável, severo, simples, - nada pernóstico". A essas categorias, enunciadas por Manuel Bandeira (1937:94-95), podem ser acrescidas as considerações de José Mariano Filho lapud Couto 1922) que, em nome da lógica e da correspondência entre a arquitetura e as necessidades do século $X X$, ataca o estilo "'bonitinho', misto de arte nova e gótica, com lambrequins suiços e marquises Luís XVI".

Mas o neocolonial acaba sendo, de fato, o último capítulo da voga eclética entre nós, resultando em outras soluções de superfície, na aplicação de novos ornatos, inspirados, em grande parte, na arquitetura portuguesa.

Ricardo Severo, apesar de ser o principal teórico da "arquitetura tradicionalista", não condena o ecletismo enquanto atitude, consciente de seu significado num país que rompia os laços coloniais. Diríamos, hoje em dia, que Severo compreende as "razões psicológicas" do ecletismo no Brasil: é o desejo de formar uma nova cultura que em nada lembrasse "a velha metrópole ou os tempos ominosos da colônia" que leva o país a mirar-se nos centros "opulentos e deslumbrantes de civilazação", a importar seus materiais a partir dos quais construiria seu futuro.

Esse tipo de compreensão só é,possível porque Severo é um homem que ainda faz parte da geração eclética. É sua crença de que na arte nacional só caberão "a análise, a seleção, a cópia e a simples acomodação das fórmulas estéticas consagradas", sendo inútil toda e qualquer tentativa de elaborar novas formas ou reviver tipos mortos. $O$ "extravagante capricho modernista", que caracterizava a arquitetura brasileira, só é criticado por ser estranho ao ambiente nacional, não por sua feição de colagem poliestilística, traço típico do Severo arquiteto, que exibe virtuosismo e variedade em seus empréstimos aos modelos portugueses dos séculos XVII e XVIII.

Bem outra é a atitude de José Mariano Filho (apud Couto 1922), que cria um sistema rígido e determinado, sem perceber a contradição de sua postura num século como o XX, portador de valores diferentes da época anterior. O neocolonial deveria inspirar-se nos modelos do passado, emprestando ao presente sua "grande plasticidade artística" e sua "beleza essencial". Estamos novamente diante de uma operação de caráter eclético, mas destituída de liberdade, que atinge, antes de tudo, uma dimensão decorativa, denominada de "exterioridades bonitinhas" por Manuel Bandeira e de borracheira adimatada pela revista Festa (vide Fabris 1987:287).

A Exposição Internacional do Centenário da Independência, realizada no Rio de Janeiro em 1922, marca o triunfo do novo estilo, considerado "símbolo da emancipação artística do país" lapud Bruand 1981:55).

Muitos dos pavilhões brasileiros são neocoloniais, despertando grande entusiasmo inclusive nos visitantes estrangeiros, que apreciam o exotismo e a cor local de suas fachadas e interiores e algumas soluções funcionais, adequadas ao clima do país. 
$\bigcirc$ apogeu do neocolonial é, porém, curto, apesar de contar com a adesão de inúmeros intelectuais nacionalistas (vide Fabris 1987:287-289).

Uma nova geração de arquitetos estava surgindo no cenário nacional e entre eles se destaca Lúcio Costa, a princípio construtor neocolonial ele também. Mas, à diferença do teórico José Mariano Filho, o arquiteto Lúcio Costa percebe que se impunha uma nova relação com o passado, não mais ditada pela adesão a um determinado léxico e sim pela compreensão dos principios funcionais inerentes às edificações coloniais, que faz consistir na franqueza dos processos construtivos e numa volumetria geometricamente definida.

Essa percepção põe fim ao capítulo eclético na história da arquitetura brasileira, preparando-a a um novo encontro com a modernidade, marcado desta vez não mais pela história, não mais por um repertório formal, mas pela busca de programas, definidos essencialmente em termos de tecnologia. (1970:200-202).

(Artigo redigido em 1990).

\section{BIBLIOGRAFIA}

ACQUARONE, F. História das artes plásticas no Brasil. Rio de Janeiro, Ed. 1980 Americana.

ARGAN, G.C. II revival. In: II revival, Milano, Mazzotta. 1974

AZEVEDO, V. de Paulo Vicente de. A pirâmide do Piques. Revista do Brasil. 1920 São Paulo, jun, 5(14).

BANDEIRA, M. Crônicas da Provincia do Brasil. Rio de Janeiro, Civilização 1937 Brasileira.

BRUAND, Y. Arquitetura contemporânea no Brasil. São Paulo, Perspectiva. 1981

COSTA, Cacilda Teixeira da. A "Saracen Foundry" de Walter MacFarlene\&Co. no 1988 Brasil. Remanescências de Glasgow. São Paulo, ECA/USP, v.1 (Monografia de Mestrado, mimeo.).

COUTO, Ribeiro. A nossa tradição arquitetônica. Correio Paulistano, 6 março. 1922

DEL BRENNA, G.Rosso. Ecletismo no Rio de Janeiro (séc.XIX/XX) In: FABRIS, 1987 Annateresa (org.) Ecletismo na arquitetura brasileira. São Paulo, Nobel. 
GRISERI, A. e GABETTI, R. Arcbitettura dell'Eclettismo. Torino, Einaudi, 1974. 1973

JENCKS. The language of postmoderm architecture. London, Academy. 1984

MIGNOT, C. L'architecture au XIX siècle. Fribourg, Office du Livre.

1983

OLSEN, D.J. The city as a work of art: London, Paris, Vienna. New Haven, Yale Uni1986 versity Press.

PEVSNER, N. Génie de L'architecture européenne. Paris, Le Livre de Poche, v.2. 1970

PINTO, A. Moreira. A cidade de São Paulo em 1900. São Paulo, Governo do Estado. 1979

QUEIROZ, M.I. Pereira de. Ainda uma definição do 'ser brasileiro'? In: RODRIGUES, 1981 L. Martins (org.). Trabalbo e cultura no Brasil. Recife, ANPPCS/ Brasília, CNPQ.

SALGUEIRO, H.Angotti. L'influence de l'architecture française du XIX siècle au 1986 Brêsil: le cas de Belo Horizonte. Université Paul Valéry, Montpellier III.

VERNE, Júlio. Viagem à Inglaterra e à Escócia. São Paulo, Nobel. 1990 
Changes in the domestic space affecting Brazilian 19th. century architecture.

Carlos Alberto Cerqueira Lemos

After a survey of colonial domestic archilecture in Brazil lincluding references to Portuguese vernacular models, indigenous contributions and adaptation to climatic conditions, geographical isolation and seggregative behaviour patterns), the author describes the main features of the diffuse pattern of rural houses, as well as its urban counterparts. Eclecticism - with its alienigenous roots - is considered the most important trend of change from the second half of the 19th - century until the First World War. UNTTERMS: Domestic space (Brazil, 19th. - century). Archictecture (colonial).

An. MP, NS 1: pg. 95, 1993.

Fontes textuais e vida material: observações preliminares sobre casas de habitação nos Campos de Goitacazes, sécs. XVIII ẹ XIX.

Sheila Siqueira de Castro Faria

A autora explora uma rica coleção de inventários dos séculos XVIII e XIX, referentes a habitantes dos Campos de Goitacazes (no atual Norte Fluminense, RI). São propostas inferências sobre vários tópicos: atributos morfológicos e tecnológicos das estruturas, padrōes de afividades. (em particular as produtivas), arranjos espaciais, sistemas de artefatos, relações com a organização familiar, a condição senvil, sistemas de valor, etc. Também se registram as mudanças observadas.

UNITERMOS: Habitação colonial (Brasil). Campos de Goitacazes RJ: organização do espaço rural (éc. $18 / 19)$.

An. MP, NS 1: pg. 107, 1993.

Written sources and material life: preliminary observations on 18 th./19th - century dwelling houses from Campos dos Goitacazes, RJ - Brazil.

Sheila Siqueira de Castro Faria

The author explores a rich collection of 18th.-19th-century inventories regarding inhabitants from Campos dos Goitacazes (the area nowadays known as "Norte Fluminense", State of Rio de Janeiro, Brazill). Inferences are made on several subjects, including morphological and technological attributes of the structures, patterns of activities (particularly the productive ones), spatial ensembles, artifact systems, relationships with family organization, servile condition, valorative systems etc. Observable changes are registered.

UNITERMS: Colonial domestic space (Brazil). Campos dos Goitacazes RJ: organization of rural space (18th.-19th centuries).

An. MP, NS 1: pg. 107, 1993.

Arquitetura eclética no Brasil: o cenário da modernização.

Annateresa Fabris

A autora acentua o significado social e cultural do Ecletismo, além do domínio da arquitetura e do nível dos fenômenos estilísticos. Este quadro lhe permite entender, de um ponto de vista histórico, suas tendéncias cenográficas, o gosto pela magnificência, a expressividade e a monumentalidade, assim como os vínculos com o passado. São então apontados alguns traços específicos do Ecletismo no Brasil, que tem entre seus ingredientes uma atitude anti-colonial. O movimento neoclássico é incluído como manifestação tardia do Ecletismo, que sobreviverá até o estabelecimento de uma nova relação com a modernidade - mediada pela tecnologia UNITERMOS: Ecletismo. Arquitetura eclética (Brasil). Ecletismo, modernidade, modernização. An. MP, NS 1: pg. 131, 1993. 
Eclecticism in Brazilian architecture: a scenery for modernization.

Annateresa Fabris

The author enhances the social and cultural meaning of Eclecticism, beyond the domain of Architecture and the level of stylistic phenomena. This frame of reference allows her to understand in a historical key its scenographical tendencies and the taste for magnificence, expressiveness and monumentality, as well as its links with the past. Some specific features of Brazilian Eclecticism are then described, as its anti-colonialistic bias. Neoclassical movement is included as a late manifestation of Eclecticism which survives until the establishment of a new kind of relationship with modernity - mediated by technology.

UNITERMS: Eclecticism. Eclecticism and architecture (Brazil). Eclecticism, modernity, modernization.

An. MP, NS 1: pg. 131, 1993.

São Paulo antigo, uma encomenda da modernidade : as fotografias de Militão nas pinturas do Museu Paulista.

Solange Ferraz de Lima e Vânia Carneiro de Carvalho

Por ocasião das comemorações do centenário da Independência do Brasil em 1922, o então diretor do Museu Paulista, Affonso de Escragnole Taunay, empenhousse na montagem de exposiç̃os voltadas para a reconstituição arcaizante do passado urbano de São Paulo. Parte desse projeto consistiv em encomendas de pinturas realizadas a partir de matrizes fotográficas do século passado. O presente estudo discute as estratégias visuais presentes na transcodificaçăo de objetos iconográficos de natureza diversa no ámbito do espaço celebrativo do Museu e seus desdobramentos ideológicos, implícitos nas ações de caráter nacionalista, 'educacional e preservacionista.

UNITERMOS: Iconologia. Pintura e modelos fotográficos. História do imaginário (São Paulo "Colonial"). História de coleçôes (Museu Paulista, décáda de 20).

An. MP. NS 1; pg. 147, 1993.

Ancient São Paulo, modernity's commission: Militão's photographs as models for oil paintings at the Museu Paulista.

Solange Ferraz de Lima e Vânia Carneiro de Carvalho

The centennial commemoration of Brazil's Independence in 1922 offered the director of the Museu Paulista at that time, Affonso de Escragnole Taunay, the opportunity to organize public exhibitions dedicated to an archaizing recreation of São Paulo's urban past. Part of this commemoration resulted in commissioning well known artists to produce oil canvasses from 19th. - century photographic sources. The present study examines the visual strategies in the translation of dissimilar iconographic media, considered within the Museum's celebrative functions, and the ideological implications in their nationalistic, pedagogic and conservational aims.

UNITERMS: Iconology. Painting and photographic models. History of the imaginaire ("Colonial" São Paulo). History of collections (Museu Paulista, 1920's)

An. MP. NS 1: pg. 147, 1993.

Sintomas do modo de vida burguês no vale do Paraiba, séc. XIX. Fazenda São Fernando, Vassouras RJ (Exploraçăo arqueológica e museológica).

Tânia Andrade Lima, Maria Cristina Oliveira Bruno e Marta Ferreira Reis da Fonseca

No âmbito de um projeto voltado para investigar arqueologicamente o surgimento do modo de vida burguês, que antecede a instalação da burquesia propriamente dita no país, vêm sendo pesquisadas unidades de produção de café implantadas em meados do século passado no Vale do Parába Fluminense. A Fazenda São Fernando, situada no município de Vassouras RJ, na condição de um dos mais notáveis exemplos do processo de expansão, apogeu e decadência desta monocultura na região, foi trabalhada com vistas a se tornar um dos espaços destinados ao conhecimento e divulgação desse passado. A Arqueologia e a 